NASA Contractor Report 195426

AIAA-95-0038

\title{
On Supersonic-Inlet Boundary-Layer Bleed Flow
}

Gary J. Harloff and Gregory E. Smith

NYMA, Inc.

Cleveland, Ohio

January 1995

Prepared for

Lewis Research Center

Under Contract NAS3-27186

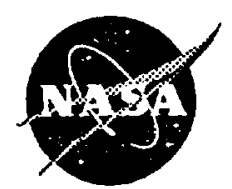

(NASA-CR-195426) ON

N95-19769

SUPERSONIC-INLET BOUNDARY-LAYER

BLEED FLOW Final Report (NYMA)

$17 \mathrm{p}$

Unclas

National Aeronautics and

Space Administration 

$-$ 


\title{
On Supersonic-Inlet Boundary-Layer Bleed Flow
}

\author{
Gary J. Harloff*and Gregory E. Smith ${ }^{\dagger}$ \\ NYMA, Inc. \\ NASA Lewis Research Center \\ Cleveland, $\mathrm{OH} 44135$
}

\begin{abstract}
Boundary-layer bleed in supersonic inlets is typically used to avoid separation from adverse shockwave/boundary-layer interactions and subsequent total pressure losses in the subsonic diffuser and to improve normal shock stability. Methodologies used to determine bleed requirements are reviewed. Empirical sonic flow coefficients are currently used to determine the bleed hole pattern. These coefficients depend on local Mach number, pressure ratio, hole geometry, etc. A new analytical bleed method is presented to compute sonic flow coefficients for holes and narrow slots and predictions are compared with published data to illustrate the accuracy of the model. The model can be used by inlet designers and as a bleed boundary condition for computational fluid dynamic studies.
\end{abstract}

\section{Nomenclature}

\begin{tabular}{|c|c|}
\hline$A$ & Area \\
\hline$A^{*} / A$ & Area ratio \\
\hline$A_{p}$ & Porous Area \\
\hline$C_{b}$ & $\begin{array}{l}\text { Coefficient in Abrahamson's } \\
\text { bleed model }\end{array}$ \\
\hline$C_{d}$ & Discharge coefficient \\
\hline$C F D$ & Computational Fluid Dynamics \\
\hline$\Delta C_{D}$ & Discharge coefficient change \\
\hline$D$ & $\begin{array}{l}\text { Bleed hole diameter or } \\
\text { hydraulic diameter }\end{array}$ \\
\hline $\begin{array}{l}\underline{e}_{N} \\
\underline{\underline{e}}_{*}\end{array}$ & $\begin{array}{l}\text { Unit vector normal to surface } \\
\text { Unit vector tangential to surface }\end{array}$ \\
\hline$\vec{H}_{i}$ & $\begin{array}{l}\text { Incompressible boundary layer } \\
\text { shape factor, } \delta^{*} / \theta\end{array}$ \\
\hline
\end{tabular}

"Senior Engineer, NYMA, Inc., Aseociate Fellow ALAA tResearch Engineer, NYMA, Inc., Senior Member ALAA Copyright $(\mathcal{C}$ by Harloft and Smith. Published by the American Institute of Aeronautics and Astronautics with permission

\begin{tabular}{|c|c|}
\hline & \\
\hline$L$ & Bleed hole plate thickness \\
\hline$M$ & Mach Number \\
\hline$p$ & Pressure \\
\hline$P_{a}$ & $\begin{array}{l}\text { Pascal } \\
\text { Local total pressure at }\end{array}$ \\
\hline$p_{t_{0}}$ & boundary layer edge \\
\hline$Q$ & $\begin{array}{l}\text { Sonic mass flow coefficient; } \\
\text { ratio of actual mass flow to } \\
\text { theoretical maximum mass flow } \\
\text { at local total conditions }\end{array}$ \\
\hline$\underset{v}{q}$ & Dynamic pressure \\
\hline $\begin{array}{c}X_{m} \\
X p\left(M_{o}, \theta\right)\end{array}$ & $\begin{array}{l}p_{a} / p_{o} \\
\text { See local static pressure } \\
\text { model }\end{array}$ \\
\hline $\boldsymbol{R}$ & Gas constant \\
\hline$R e$ & Reynolds number \\
\hline$V_{b}$ & Bleed velocity normal to a wall \\
\hline $\begin{array}{l}\gamma \\
\delta^{* \prime}\end{array}$ & $\begin{array}{l}\text { Ratio of specific heats }=1.4 \\
\text { Boundary layer displacement } \\
\text { thickness }\end{array}$ \\
\hline$\theta$ & $\begin{array}{l}\text { Boundary Layer momentum } \\
\text { thickness, or bleed hole angle } \\
\text { relative to local surface }\end{array}$ \\
\hline$\rho$ & Density \\
\hline$\phi$ & Porosity \\
\hline & Subscripts \\
\hline $0, a$ & Freestream, ambient \\
\hline 1 & Behind a normal shock \\
\hline 2 & Bleed duct exit \\
\hline$b l$ & Bleed \\
\hline$e$ & Boundary layer edge \\
\hline pl & Bleed plenum \\
\hline$s$ & Static condition \\
\hline$t$ & Total condition \\
\hline$t h$ & Theoretical \\
\hline$w$ & Wall \\
\hline
\end{tabular}




\author{
Superscripts \\ $\begin{array}{cl}* & \text { Sonic } \\ L / D & \text { Length/Diameter } \\ P & \text { Pressure effect }\end{array}$
}

\section{Introduction}

Boundary-layer bleed in supersonic inlets is typically used to avoid boundary layer flow separation from adverse shock-wave/boundary-layer interactions and subsequent total pressure loes in the subsonic diffuser and to stabilize the normal shock. Currently bleed flow rates are determined from empirical sonic flow coefficients which are measured in wind tunnels for specified Mach numbers and boundary-layer profiles. These coefficients depend on local Mach number, pressure ratio, hole or slot geometry, length-to-diameter ratio, etc. Because of scale effects relative to $L / D$ and $D / \delta^{*}$, these data may not readily scale to full scale. It is the purpose of this paper to review current boundary-layer bleed removal design practice and to present a new analytical model for bleed hole and narrow slot sonic flow coefficients. Model predictions are compared with published test data to illustrate the accuracy of the model.

\section{Inlet Bleed Considerations}

Syberg and Hickcox ${ }^{1}$ presented a methodology to determine bleed band locations and bleed flow rates for supersonic inlets. They examined an inlet with a design Mach number of 3.5 with a centerbody translation schedule which maintained the throat Mach number at 1.25 in the mixed-compression operation range. Boundary-layer profiles were determined and values of boundary-layer incompressible shape factor, $H_{i}$, were computed. Values of 1.3 correspond to fully developed profiles and values between 1.8 and 2.0 correspond to profiles which are typically bled to avoid boundary-layer flow separation in regions of shock waves or diffused flow. Several bleed regions of two to five rows were used and the plenums for each bleed region were partitioned to prevent reverse flow in regions of shock impingement. The bleed bands were positioned to remove low momentum boundary layer flow near the wall in order to obtain acceptable incompressible shape factors over the mixed-compression operating range. To minimize bleed drag, 20 deg holes, relative to local surface, were used on the centerbody and forward cowl bleed regions. In the throat re- gion, $90 \mathrm{deg}$ holes were used for normal shock stability. The diameter was sized such that $D / \delta^{*}=1.0$. They noted that the boundary layer growth rate increased in the bleed region due to surface roughness and mixing of high and low energy air in the boundary layer.

Actual inlet bleed rates are typically 25\% (Syberg and Hickcox ${ }^{1}$ ) higher than theoretical bleed flow rates (computed to reduce $H_{i}$ to acceptable levels) in order to compensate for these roughness and mixing effects which are difficult to model correctly. Recently Paynter et al. ${ }^{2}$ addressed these issues with an increased roughness near wall length scale, in the algebraic turbulence model of Cebeci-Chang ${ }^{3}$, correlated with bleed mass flow. The roughness length scale decreased to zero when the bleed holes were choked.

Tjonneland ${ }^{4}$ indicated that required inlet bleed decreases with increasing inlet scale because smaller inlet models tend to have larger $D / \delta^{*}$ bleed holes. This larger $D / \delta^{*}$ increases the boundary layer growth rate across bleed regions and this was attributed to vortex shedding from the bleed holes. Values of $D / \delta^{*}$ of 0.5 in the forward cowl region and 1.0 in the throat region were typical of full scale. Values of $D / \delta^{*}$ of 2 on small scale inlet models required higher bleed rates. Sonic flow coefficients, $Q$, were presented for $\frac{1}{6}$ scale and full scale supersonic transport inlets for a design $M_{0}$ of 2.7. The $L / D$ of the bleed holes was 4.8 to 5.6 for the $\frac{1}{6}$ scale model and 2.2 to 2.9 for the full scale inlet. Thus scaling parameters of $L / D$ and $D / \delta^{*}$ were identified. At cruise the predicted total inlet bleed drag for the four inlets (total bleed rate $13.6 \%$ of capture flow) represented a loss in range of $6 \%$.

Bowditch $^{5}$ developed a linear correlation of the boundary-layer bleed/capture flow vs wetted area/throat area for several $2 D$ and axisymmetric inlets for $M_{0}$ of 2.5 to 3.5. Bleed rates as high as $14 \%$ of capture flow are reported at $40 \%$ wetted area/throat area. A typical inlet boundary layer bleed schedule vs Mach number is specific by $\mathrm{He}$ witt and Johnston ${ }^{6}$, and indicates that the bleed flow removal increases with Mach number. For example, at Mach 2.5 about 2.5\% of capture flow is removed and at Mach 7 about $14 \%$ is removed. These references provide only guidance; the location and amount of bleed required for a given inlet is determined empirically in a wind tunnel. For example, during a recent Mach 5 inlet test, Weir ${ }^{7}$ indicated that about $40 \%$ of the wind tunnel time was de- 
voted to bleed optimization studies.

Wong ${ }^{8}$ reported successful suppression of shock induced boundary-layer separation with a bleed rate of up to $3 \%$ of capture flow for a normal shock of $M_{0}=1.9$. The bleed system was compartmentalized, had $30 \%$ porosity, and normal holes of diameter $\delta^{*}$. Continuous bleed upstream and through the shock-wave boundary-layer interaction region was needed. He proposed a bleed criteria whereby the local boundary layer total pressure minus normal shock total pressure loss has to be greater than the downstream static pressure to avoid boundarylayer flow separation. Boundary layer flow with total pressure less than this "critical" value should be removed. From $M_{e}$ of 1.37 to 3.0 the $M_{\text {eritical }}$ vs $M_{e}$ relationship is linear. For example, at $M_{e}$ of 3.0 the critical Mach number is 2.71 and at 1.37 the critical Mach number is 1.09. For the latter case, all boundary layer flow below Mach 1.09 would be removed to satisfy this bleed criteria. Thus this method provides another criteria to select the amount of bleed needed to prevent boundary-layer flow separation at shock wave impingement locations.

\section{Prior Modeling Work}

Several modeling approaches have been used in the past to model the bleed flow in supersonic inlets. These approaches include using nozzle equations, Darcy's law for porous plates, and specifying the local sonic flow coefficient, $Q$, as a constant or by a table look up procedure. In CFD codes, the mass flux at the wall is usually required as a bleed boundary condition which can either be specified as a constant within a bleed band or allowed to vary with local flow conditions.

Abrahamson ${ }^{9}$ modeled the bleed velocity, $V_{b}$, across the plate using a nozzle equation. For unchoked flow, $P_{p l} / P_{t o}>0.528$

$$
V_{b}=\frac{C_{b} P_{p l} A_{p}}{p_{w} \sqrt{T_{W}}} \sqrt{\left(\frac{p_{t w}}{P_{p l}}\right)^{\frac{\gamma-1}{\gamma}}\left[\left(\frac{p_{t w}}{p_{p l}}\right)^{\frac{\gamma-1}{\gamma}}-1\right] \frac{2 \gamma}{R(\gamma-1)}}
$$

for choked flow, $P_{p 1} / P_{t w} \leq 0.528$

$$
V_{b}=\frac{C_{b} p_{t w} A_{p}}{\rho_{w} \sqrt{T_{t w}}} \sqrt{\frac{\gamma}{R}}\left(\frac{\gamma+1}{2}\right)^{\frac{\gamma+1}{2(\gamma-1)}}
$$

where $A_{p}$ is the porous area and $C_{b}$ was assumed to be 0.2 . The tangential velocity was assumed to be zero. This model ignores the aerodynamic controlling area or vena contracta affect on the flow velocity. It is a hypothesis of the present paper that flow through bleed holes is better modeled as orifice flow.

Benhachmi ${ }^{10}$ experimentally determined that, for a porous surface, the flow correlation developed for low velocity normal flow also applied for parallel flow at Mach numbers of 2.5 and 3.0. The pressure drop through the porous material was modeled as a function of velocity squared, e.g.

$$
\frac{\Delta p}{\rho V_{b}^{2}}=212.70+\frac{7588.0}{R e}
$$

where $R e$ is based on the thickness of the porous material.

Chokani and Squire ${ }^{11}$ used a linear Darcy law equation to compute bleed velocity through a plate with holes. The equation was developed in a calibration rig, and used to compute flow through a bleed plate at transonic Mach numbers. The equation is:

$$
\frac{V_{b}}{U_{0}}=0.4 \sqrt{\frac{\Delta p}{\rho U_{0}^{2}}}
$$

The calibration rig data was linear over the $\Delta p$ range of the experiment from $700 P_{a}$ to $4000 P_{a}$. In the development of this equation for transonic flow application, the effects of boundary layer displacement thickness, local Mach number and compressibility effects have been ignored.

Rallo ${ }^{12}$ also used Darcy's law to model flow through 4 different porous plates at $M_{0}=6$. The equation is:

$$
\frac{V_{b}}{U_{o}}=\frac{\sigma}{\rho_{o} U_{o}^{2}}(\Delta p)
$$

where $\sigma$ was varied from 0.1 to 0.3 . Porosity varied from 22 to $28 \%$.

Mayer and Paynter ${ }^{13}$ recently modeled the bleed boundary condition by computing the wall normal mass flow based on local flow properties, total bleed hole area, and empirical sonic flow coefficients. The study used empirical sonic flow coefficient data for 90 and 20 deg holes from Syberg and Hickcox ${ }^{1}$ and McLafferty ${ }^{14}$ respectively. These coefficients are obtained by a table look up procedure at each boundary grid point in the bleed region. This procedure is limited by the range of the empirical data in the table. 
Chyu et al. ${ }^{15}$ investigated nine different bleed boundary conditions for CFD simulations of supercritical flow through an axisymmetric inlet at $M_{0}=2.65$. Three boundary conditions were used successfully to stabilize the terminal shock downstream of the inlet throat. Two of these did not utilive experimental pressure data. For choked bleed, the preferred boundary condition used:

$$
V_{N}=C_{d} \sqrt{\frac{\gamma p}{\rho}}
$$

where the two models assumed either $C_{D}=0.07$ or $C_{D}=0.025+0.065 \underline{e}_{N} \cdot \underline{e}_{*}$.

\section{New Bleed Model; Hole or Narrow Slot}

A new bleed modeling approach is presented which is based on conservation of mass, momentum and energy for flow through a single hole or slot and empirical relations. The approach permits the local sonic flow coefficient to vary with local flow conditions, hole or slot geometry, and orientation.

The bleed duct is modeled like a pitot inlet with a detached normal shock when the boundary layer edge Mach number is supersonic. For low $L / D$ orifices, $L / D \leq 3$, the minimum aerodynamic area is downstream of the orifice and is called a vena contracta. Figure 1 presents schematics of flow through low, intermediate, and high $L / D$ orifices where there is no external flow. Sonic flow first occurs within the vena contracta; decreasing the downstream pressure will move the vena contracta toward the low $L / D$ orifice, see Fig. 1a. When the Mach 1 surface reaches the orifice the flow is only influenced by the upstream flow conditions. As shown in Fig. $1 \mathrm{~b}$ for intermediate length orifices, $1 \leq L / D \leq 3$, the streamline patterns are similar to that of the low $L / D$ orifice. For high $L / D$ orifices, $L / D>6$, the vena contracta is within the orifice and the flow chokes without an appreciable increase in the vena contracta area. Thus the low $L / D$ orifices can increase the flow after reaching Mach one flow, whereas the longer orifices do not appreciably increase the flow after reaching Mach one. Friction losses are associated with finite length holes or slots. These losses have been modeled using Fanno friction losses, but for simplicity the losses are accounted for by a decrease in $C_{D}$ for $L / D>3$. Effects of $M_{0}$, and $p_{2} / p_{0}, L / D$, and $\theta$ are modeled empirically.

The flow through a low $L / D$ orifice, of angle $\theta$, is shown schematically in Fig. 2, with supersonic local flow. Boundary layer flow separation is indicated on both sides of the orifice and a "spillage" normal shock is detached. The internal and external flow field communicate through the separated boundary layer until the vena contracta moves into the orifice. Stations used in the model are identified in Fig. 2. CFD studies by Chyu et al. ${ }^{16}$ have illustrated a similar shock structure as indicated in Fig. 2. for a $90 \mathrm{deg}$ hole and indicated that boundary layer flow separation is present for $90 \mathrm{deg}$ holes and not for 30 deg holes. Boundary layer separation inside a 90 deg bleed slot has been reported by Hahn and Shih $^{17}$ and Davis et al. ${ }^{18}$.

\section{Sonic Flow Coefficient Bleed Model}

The freestream total to static pressure is:

$$
\left(\frac{p_{t}}{p_{s}}\right)_{0}=\left[1+0.2 M_{0}^{2}\right]^{3.5}
$$

If $M_{0} \cos \theta>1$ and $\theta>50 \mathrm{deg}$, the normal shock pressure jump is:

$$
\frac{p_{1}}{p_{a}}=\frac{7\left(M_{0} \cos \theta\right)^{2}-1}{6}
$$

The exit static to local static pressure is:

$$
\frac{p_{2}}{p_{o}}=\frac{p_{2}}{p_{t_{e}}}\left(\frac{p_{t_{e}}}{p_{a}}\right)\left(\frac{p_{a}}{p_{o}}\right)
$$

where $p_{a} / p_{o}$ accounts for a reduction in static pressure from station 0 to station a, see Fig. 2 and the Local Static Pressure station below. For $\theta>50 \mathrm{deg}$ $p_{a} / p_{0}=1.0$.

The bleed hole exit Mach number,

$$
\begin{aligned}
& M_{2}=\sqrt{5\left(\frac{p_{2}}{p_{0}}\right)^{-2 / 7}-5} \\
& M_{2} \leq 1
\end{aligned}
$$

where $p_{0}$ is assumed to be the effective local total pressure at station 2. If friction losses are computed, then $p_{t_{2}}$ would be computed. The $A^{*} / A$ ratio at the bleed hole exit is:

$$
\left(\frac{A^{*}}{A}\right)_{2}=\frac{216}{125} M_{2}\left[1+0.2 M_{2}^{2}\right]^{-3}
$$

The sonic exit area is:

$$
A_{2}^{*}=A_{b l}\left(\frac{A^{*}}{A}\right)_{2}
$$

The exit mass flow is: 


$$
w_{2}=0.532 A_{2}^{*} p_{0} / \sqrt{T_{t_{0}}}
$$

for hole angles other than 90 deg there is a ram effect described in the Ram Effect section below.

The sonic flow rate is:

$$
w^{*}=0.532 A_{\mathrm{bl}} p_{t o} / \sqrt{T_{10}}
$$

The theoretical sonic flow coefficient, $Q_{T H}$ is:

$$
Q_{\mathrm{TH}}=\frac{w_{2} C_{D}}{w^{*}}
$$

where $C_{D}=C_{D}\left(C_{D_{\bullet}}, p_{2} / p_{0}, \theta, M_{0}, L / D, \ldots\right)$ and $w^{*}$ is the sonic flow rate at local total pressure and total temperature. The Bragg ${ }^{19}$ model is used to determine the discharge coefficient pressure ratio dependence.

\section{Compressible Discharge Coefficient}

\section{Vena Contracta Effect}

Studies by Jobson ${ }^{20}$ provide an analytical framework for the modeling of the vena contracta area ratio variation with pressure ratio, $p_{2} / p_{0}$. He assumed that the velocity profile upstream and parallel to the orifice centerline was independent of flow rate and this is also assumed here for $M_{0}=0.0$. Bragg $^{19}$ extended Jobson's analysis procedure to account for compressibility effects, and the Bragg analysis is used to determine a baseline discharge coefficient of the orifice. The discharge coefficient is equal to the vena contracta area divided by the orifice area. The details can be found in Bragg ${ }^{19}$. This $C_{D}$ is then modified empirically to account for $M_{o}, L / D$, and $\theta$ effects. The details of the $C_{D}$ buildup are given below and summarized in Table I.

The pressure ratio across the orifice is increased by the normal shock pressure jump (at freestream Mach number) where $\theta \leq 50 \mathrm{deg}$. When $\theta>50 \mathrm{deg}$ the normal shock is absent.

If $M_{0}=0, C_{D}=C_{D_{0}}$ where $C_{D_{0}}=0.82$ for holes and 0.74 for narrow slots. The constant $C_{D_{\text {。 }}}$ at $M_{0}=0$ assumes that the velocity profile into the orifice is independent of pressure ratio. For 0 $<M_{0} \leq 0.6$ the orifice discharge coefficient is an average of $C_{D_{0}}$ and $C_{D}$ computed by the model.

\section{Flow Separation}

The sonic discharge coefficient decreases with increasing freestream, or boundary layer edge, Mach number as shown in Figure 3. The relationship is approximated over three zones. For subsonic flow, $0.0<M_{0} \leq 0.6$, a gradual reduction is $C_{D}^{*}$ is observed probably due to convection effects on the inlet velocity profiles. The sharper reduction in $C_{D}^{*}$, from $0.6<M_{0} \leq 1.6$, is thought to be due to boundary-layer flow separation outside and/or inside the bleed hole (slot). Above $M_{0}=1.6$ the separation pattern is apparently self similar. These relationships are empirically determined using the mathematical model to determine differences in sonic $C_{D}^{*}$ with $M_{0}$ and experimental data. The relationships of $\Delta C_{D}^{*}$ vs $M_{0}$ are listed in Table 1.

\section{Pressure Ratio Effect}

The discharge coefficient is reduced to account for internal flow separation. For bleed hole angles greater than $50 \mathrm{deg}$, pressure ratio, $\frac{p_{2}}{p_{0}} \geq 0.5$, and local Mach number greater than 0.84,

$$
\Delta C_{D}^{P}=-0.46\left(\frac{p_{2}}{p_{o}}-0.5\right)
$$

\section{Hole Angle Effect}

The reduction in $C_{D}$ is assumed to be zero for $\theta \leq 50 \mathrm{deg}$ holes (or narrow slots) and linear for larger angles. The equation follows:

$$
\begin{gathered}
\text { slope }\left.\right|_{\theta}=\left(\frac{1-0}{90^{\circ}-50^{\circ}}\right)=0.025 \\
\Delta C_{D}^{\theta}\left(\frac{p_{2}}{p_{0}}, \theta\right)=\Delta C_{D}^{P}(0.025)\left(\theta-50^{\circ}\right) ; \\
50^{\circ} \leq \theta \leq 90^{\circ} \\
\Delta C_{D}^{\theta}\left(\left(\frac{p_{2}}{p_{0}}\right), \theta\right)=0 ; \theta \leq 50^{\circ}
\end{gathered}
$$

It is hypothesized that, for $M_{0} \cos \theta>1$ and $\theta \geq$ $50 \mathrm{deg}$, internal and external boundary-layer flow separation are coupled aerodynamically until the flow is choked. This phenomena may be responsible for the increase in turbulence previously ascribed to "roughness".

\section{Ram Effect}

For 90 deg bleed holes, the bleed entrance total pressure is local freestream static pressure. For hole angles less than 90 deg the total pressure at the 
bleed hole entrance is assumed to be proportional to the dynamic pressure directed into the bleed hole (or slot) and any normal shock total pressure loss, i.e.

$$
\frac{q}{p_{0}}=\frac{\gamma}{2} \operatorname{const}(\theta)\left(M_{0} \cos (\theta)\right)^{2}\left(\frac{p_{t_{1}}}{p_{t_{0}}}\right)
$$

where the loss in total pressure due to a normal shock for $M_{0}>1$ is:

$$
\frac{p_{t_{1}}}{p_{t_{0}}}=\left(\frac{6 M_{0}^{2}}{M_{0}^{2}+5}\right)^{3.5}\left(\frac{6}{7 M_{0}^{2}-1}\right)^{2.5}
$$

The upstream Mach number is assumed to be $M_{0}$. and

$$
w_{2}=.532 A_{z_{2}} p_{\circ}\left(1+\frac{q}{p_{0}}\right) / \sqrt{T_{t_{0}}}
$$

The const $(\theta)$ is given below

\begin{tabular}{rl}
$\theta$, deg & const $(\theta)$ \\
\hline 0 & 1.0 \\
20 & 0.7 \\
40 & 0.2 \\
90 & 0.0
\end{tabular}

A curvefit of const $(\theta)$ vs $\theta$ can be used to determine values of $\operatorname{const}(\theta)$ for other values of $\theta$.

\section{Local Static Pressure}

The bleed entrance static pressure is assumed to decrease with increasing $M_{0}$ for low bleed hole (or slot) angles, $\theta$, as the flow accelerates through the turn. The pressure reduction begins at $M_{0}=0.2$ and continues until $M_{0}=1.2$, and is constant above $M_{0}=1.2$. The equation used is:

$$
\begin{aligned}
& X_{M}= \frac{p_{a}}{p_{0}}=1.0 ; \quad 0<M_{0} \leq 0.2 \\
& X_{M}= 1.0+\left(\frac{X P\left(M_{0}, \theta\right)-1.0}{1.2-.2}\right)\left(M_{0}-0.2\right) \\
& 0.2<M_{0}<1.2 \\
& X_{M}=X P\left(M_{0}, \theta\right) ; M_{0} \geq 1.2
\end{aligned}
$$

where $X P\left(M_{0}, \theta\right)$ is given below:

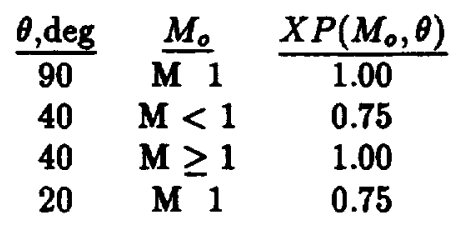

Interpolation is required for other hole (or slot) angles.

\section{$L / D$ Effect}

For $L / D$ of 3 or greater the $C_{D}$ is reduced by 0.08 to account for a higher friction loss in the larger passage configuration. Also, for narrow slots with low $L / D$, the $C_{D}$ is lowered by 0.08 to account for added separation losses over the hole configuration. Alternatively, friction effects have been modeled as a Fanno friction lose which reduce the exit total pressure and mass flow. In the interest of simplicity the $L / D$ losses are, for the present time, modeled as a constant decrease in $C_{D}$.

\section{Comparison with test data}

The single 90 degree bleed hole data with diameter $=\frac{1}{8}$ in., of Davis et al. ${ }^{21}$ were modeled. Figures 4 and 5 cover subsonic and supersonic flow with Mach number ranges 0.0 to 0.6 and 1.4 to 2.0 respectively. As the local edge Mach number increases, the sonic flow coefficient, $Q$, decreases. The predicted bleed rates are in good agreement with the test data for both subsonic and supersonic Mach numbers. The data can be collapsed onto subsonic and supersonic curves by normalizing the flow coefficient by $p_{t_{0}} / p_{o}$ and $p_{t_{1}} / p_{t_{0}}$ and plotting vs $\left(p_{0}-p_{2}\right) / p_{t_{0}}$, see Fig. 6. Smith ${ }^{22}$ first suggested plotting $Q p_{t_{0}} / p_{0}$ vs. $\left(p_{0}-p_{2}\right) / p_{t_{0}}$.

Experimental and analytical $20 \mathrm{deg}$ single hole bleed data of Davis et al. ${ }^{21}$ are shown in Fig. 7 over the Mach number range from 0.0 to 2.0. The analytical model predicts the data reasonably well.

Similar bleed flow rate data for multi-hole bleed plate tests for Mach 0.8 to 2.2, from Syberg and Koncsek $^{23}$, are illustrated in Figs. 8, 9, and 10 for $90^{\circ}, 40^{\circ}$, and $20^{\circ}$ holes respectively. The data in Fig. 8 are originally from Dennard ${ }^{24}$ and McLafferty ${ }^{14}$. The model predictions compare reasonably well with the test data, with the supersonic data modeled more accurately than the transonic data. Additional multi-hole data by Willis, Davis and Hingst ${ }^{25}$ are compared with model prediction in Fig. 11 and the data are accurately predicted at $M_{0}=1.58,1.97$ and 2.46. The data at $M_{0}=$ 1.27 are not well predicted and this is under investigation. Slot data at the same Mach numbers, from Willis, Davis, and Hingst ${ }^{25}$ show similar good agreement at the three higher Mach numbers as illustrated in Fig. 12. The slot is $1 \mathrm{~cm}$ wide and 
$1 \mathrm{~cm}$ deep. Figure 13 compares model predictions with experimental data, Davis et al. ${ }^{21}$, for a single hole bleed over a Mach number range from 0 to 2.5 for $L / D$ of 1 . The agreement is good except at the nominal Mach 1.3 condition. Possible reasons for the discrepancies from $M_{0} 1.27$ to 1.37 include: model $\Delta C_{D}^{*}\left(M_{0}\right)$ is not correct (see Fig. 3 and equation in Table 1 ), wind tunnel $M_{0}$ not accurate, etc. The data scatter present in Fig. 3 is worse from $M_{0} 1.25$ to 2.0. More research is needed to understand the data scatter.

The test data of McLafferty ${ }^{14}$ are compared with model predictions for 90,40 , and 20 deg multi-holes in Figs. 14, 15, and 16 respectively. The plates used had two rows of holes. This data is for $L / D$ of 6.0 and the discharge coefficient was lowered by 0.08 as discussed previously. The agreement with the model results is encouraging. Additional subsonic single hole 20 deg data from Davis et al. ${ }^{21}$ are compared with model predictions in Fig. 17. The subsonic exit Mach number portion of the vertical curves differ from the model predictions. Comparing the 20 deg test data for multi holes, Fig. 16, and single hole data, Fig. 17, indicates a multi hole interaction, or a possible viscous effect.

A significant contribution of the analytical bleed model is that the original premise, that a single hole model can be used to model multiple holes, has been validated. This suggests that smaller more economical wind tunnels can be utilized to generate flow coefficient data. More aerodynamically efficient hole shapes are good candidates for single hole testing.

\section{Conclusions}

An analytical model for boundary layer bleed holes and slots has been developed. The basis for the model is compressible flow through a single duct with a model for the vena contracta which controls the aerodynamic area downstream of the duct in the plenum for short $L / D$ holes or slots. Empirical adjustments were made to account for $L / D, M_{0}$, and bleed hole or slot angle effects. The new model predictions compare favorably with most of the known existing test data for both holes and narrow slots at $90 \mathrm{deg}$, and holes at 40 , and $20 \mathrm{deg}$. The model should be useful to inlet designers and as a bleed boundary condition in CFD codes where bleed has to be computed from local flow conditions, plenum pressure, and the hole or slot geometry.

Several insights were gained from the bleed model. For the 90 deg holes and narrow slots the $\Delta C_{D}^{*}$ gradually decreases from Mach number 0.0 to 0.6 where $\Delta C_{D}^{*}$ decreases further with increasing Mach number. Above $M=1.6, \Delta C_{D}^{*}$ does not decrease further. This is interpreted as follows: at low subsonic Mach numbers convection effects decrease the sonic flow coefficient. Boundary-layer flow separation in the holes or narrow slot begins at $M_{0}=0.6$ and increasingly grows until the edge Mach number reaches 1.6. At higher Mach numbers the boundary-layer flow separation patterns does not change. For holes and slots at angles less than $50 \mathrm{deg}$, three flow effects were modeled: (1) a ram effect was added to the inflow pressure, (2) the static pressure acting at the hole entrance was reduced, and (3) the decrease in $\Delta C_{D}^{*}\left(M_{0}\right)$ was set to zero since there is no flow separation model needed inside the holes or slots. Due to the perceived boundary-layer flow separation present in bleed passages for $\theta>50 \mathrm{deg}$, there is an apparent opportunity to increase $Q$ by providing more aerodynamic efficient flow passages. Flow coefficients are higher for holes than narrow slots probably due to more severe boundary-layer flow separation in slots.

\section{Acknowledgements}

This project was supported by NASA Lewis Research Center under contract NAS3-27186. The support provided by the NASA contract monitor, Robert E. Coltrin, is appreciated. The assistance of Tammy Langhals is gratefully acknowledged.

\section{References}

${ }^{1}$ Syberg, J. and Hickcox, T.E., "Design of a Bleed System for a Mach 3.5 Inlet", NASA CR-2187, January 1973.

'Paynter, G.C., Treiba, D.A. and Kheeling, W.D., "Modeling Supersonic Boundary-Layer Bleed Roughness", J. Propulsion and Power, Vol. 9, No. 4, July-August 1993, pp. 622-627.

${ }^{3}$ Cebeci, T. and Chang, K.C., "Calculation of Incompressible Rough-Wall Boundary Layer Flows", AIAA Journal, Vol. 16, No. 7, 1978, pp. 730-731.

${ }^{4}$ Tjonneland, E., "The Design, Development, and Testing of a Supersonic Transport Intake System", Inlets and Nozzles for Aerospace Engines, AGARDCP-91-71, 1971, pp. 18-1 to 18-17.

${ }^{5}$ Bowditch, David N., "Some Design Considerations for Supersonic Cruise Mixed Compression Inlets", NASA TM-71460, Nov. 1973. 
${ }^{6}$ Hewitt, F.A., Johnston, M.C., "Propulsion System Performance and Integration for High Mach Air Breathing Flight", High-Speed Flight Propulsion, Vol. 137, Prorress in Astronautics and Aeronautics, AIAA, N.Y. 1991, pp. 101-142, Seebass, A.R., editor.

${ }^{7}$ Weir, L.J., Personal Communications, September 1993.

${ }^{8}$ Wong, W.F., "The Application of Boundary Layer Suction to Suppress Strong Shock-Induced Separation in Supersonic Inlets", ALAA Paper 74 1063.

${ }^{9}$ Abrahamson, K.W., "Numerical Investigation of a Mach 3.5 Axisymmetric Inlet With Multiple Bleed Zones", AIAA Paper 88-2588.

${ }^{10}$ Benhachmi, D., Greber, I., and Hingst, W., "Experimental and Numerical Investigation of the Effect of Distributed Suction on Oblique Shock Wave/Turbulent Boundary Layer Interaction”, NASA TM-101334, August, 1988.

${ }^{11}$ Chokani, N., and Squire, L.C., "Transonic Shockwave/Turbulent Boundary Layer Interactions on a Porous Surface", Aeronartical Journal, May 1993, pp. 163-170.

${ }^{12}$ Rallo, R.A., "An Investigation of Passive Control Methods for Shock-Induced Separation at Hypersonic Speeds", M.S. Thesis, U. of Michigan, 1992.

${ }^{13}$ Mayer, D.W., and Paynter, G.C., "Boundary Conditions for Unsteady Supersonic Inlet Analyses", ISABE 93-7104, pp. 1062-1070.

${ }^{14}$ McLafferty, G., Ranard, E., "Pressure Losses and Flow Coefficients of Slanted Perforations Discharging from Within a Simulated Supersonic Inlet”, R- 0920-1, United Aircraft Corporation, 1958.

${ }^{15}$ Chyu, W.J., Howe, G.W., Shih, T.I-P., "Bleed Boundary Conditions for Numerically Simulated Mixed-Compression Supersonic Inlet Flow", J. of Propulsion and Power, Vol. 8, No. 4, July-August 1992, pp. 862 - 868.

${ }^{16}$ Chyu, W.J., Rimlinger, M.J., and Shih, T.I-P., "Effects of Bleed-Hole Geometry and Plenum Pressure on Three-Dimensional Shock-Wave/BoundaryLayer/Bleed Interactions", AIAA Paper 93-3259, July, 1993.

${ }^{17}$ Hahn, T.O., and Shih, T.I-P., "Numerical Study of Shock-Wave/Boundary-Layer Interactions with Bleed", AIAA Journal, Vol. 31, No. 5, May 1993, pp. 869 - 876.

${ }^{18}$ Davis, D.O., Willis, B., Hingst, W., "Flowfield Measurements of Slot-Bleed/Oblique Shock-Wave and Interaction, AIAA Paper 95-0032, 1995.

${ }^{19}$ Bragg, S.L., "Effect of Compressibility on the
Discharge Coefficient of Orifices and Convergent Nozzles" J. Mech. Engr. Science, Vol. 2 No. 1 1960 , pp. 35 - 44.

${ }^{20}$ Jobson, D.A., "On the Flow of a Compressible Fluid Through Orifices", Proc. Inst. Mech. Engr., London, Vol. 1 69, No. 37, 1955.

${ }^{21}$ Davis, D.O., Hingst, W.R., Bodner, J.P., "Flow Coefficient Behavior for Isolated Normal and 20 Degree Boundary Layer Bleed Holes”, NASA TM 106816, 1995.

${ }^{22}$ Smith, G.E., "Bleed Modeling", Workshop in Inlet Bleed Modeling, NASA Lewis, September 2829, 1993.

${ }^{23}$ Syberg, J., and Koncsek, J.L., "Bleed System Design Technology for Supersonic Inlets", AIAA Paper 72-1138, November 1972.

${ }^{24}$ Dennard, J.S., "A Transonic Investigation of the Mase-Flow and Pressure Recovery Characteristics of Several Types of Auxiliary Air Inlets", RM L57B07, NACA, 1957.

${ }^{25}$ Willis, B.P., Davis, D.O., Hingst, W.R., "Flow Coefficient Behavior for Boundary Layer Bleed Holes and Slots", AIAA Paper 95-0031, 1995. 
Table 1 - Model for Discharge Coefficient $C_{D}$ and Buildup $\Delta C_{D}$

\begin{tabular}{|c|c|c|}
\hline Design Space & $\begin{aligned} C_{D}= & C_{D}\left(p_{2} / p_{0}, \theta\right)+ \\
& \Delta C_{D}^{P}+\Delta C_{D}^{*}+\Delta C_{D}^{L / D}\end{aligned}$ & Effect Modeled \\
\hline Baseline & $C_{D}\left(\frac{p_{2}}{p_{2}}, \theta\right)$ & Bragg model \\
\hline$M_{0}=0,90$ deg hole & $C_{D_{0}}=0.82$ & $\begin{array}{l}\text { geometry dependent } \\
\text { no internal separation }\end{array}$ \\
\hline 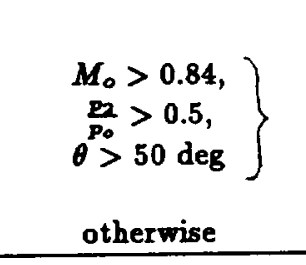 & $\begin{array}{l}\Delta C_{D}^{P}=-0.46\left(\frac{p_{2}}{p_{0}}-0.5\right) \\
\Delta C_{D}^{P}=0.0\end{array}$ & $\begin{array}{l}\text { Pressure Ratio } \\
\text { internal flow separation } \\
\text { no separation }\end{array}$ \\
\hline $\begin{array}{c}0<M_{0} \leq 0.6 \\
0.6<M_{0} \leq 1.0 \\
1.0<M_{0} \leq 1.6 \\
M_{0}>1.6\end{array}$ & $\begin{array}{l}\text { see Figure } 3 \\
\Delta C_{D}^{*}\left(M_{0}\right)=-0.1 M_{0} \\
\Delta C_{D}^{*}\left(M_{0}\right)=-0.06-0.4\left(M_{0}-0.6\right) \\
\Delta C_{D}^{*}\left(M_{0}\right)=-0.22-0.217\left(M_{0}-1.0\right) \\
\Delta C_{D}^{*}\left(M_{0}\right)=-0.35\end{array}$ & $\begin{array}{l}\text { Flow Separation, } \theta=90^{\circ} \\
\text { sonic } C_{D} \text { correction } \\
\text { convection effects } \\
\text { separation starting } \\
\text { shock effect on } \\
\text { separation } \\
\text { separation profile } \\
\text { self similar } \\
\end{array}$ \\
\hline $\begin{array}{l}\theta>50 \mathrm{deg} \\
\theta<50 \mathrm{deg}\end{array}$ & $\begin{array}{l}\Delta C_{D}^{*}=\Delta C_{D}^{*} \frac{\partial C_{D}^{*}}{\theta \theta} \Delta \theta \\
\frac{\theta C_{D}^{*}}{\theta \theta}=\frac{1-0}{90 \mathrm{deg}-50 \mathrm{deg}}=0.025 \\
\Delta C_{D}^{*}=0\end{array}$ & $\begin{array}{l}\text { Flow Separation, } \theta<90^{\circ} \\
\text { bleed hole angle effect } \\
\text { on separation } \\
\text { no separation }\end{array}$ \\
\hline $\begin{array}{l}\text { hole } L / D<3 \\
\text { hole } L / D \geq 3 \\
\text { slot } L / D<3 \\
\text { slot } L / D \geq 3 \\
\end{array}$ & $\begin{array}{l}\Delta C_{D}^{\mathrm{L} / \mathrm{D}}=0.08 \\
\Delta C_{D}^{\mathrm{L} / D}=0.00 \\
\Delta C_{D}^{\mathrm{L} / \mathrm{D}}=0 \\
\Delta C_{D}^{\mathrm{L} / \mathrm{D}}=-0.08\end{array}$ & $\begin{array}{l}L / D \text {, hole or slot } \\
\text { hole is baseline } \\
\text { internal friction loss } \\
\text { slot has more boundary } \\
\quad \text { layer separation } \\
\text { loss than hole } \\
\text { internal friction loss } \\
\end{array}$ \\
\hline $\begin{array}{c}M_{0}=0 \\
0<M_{0}<0.6\end{array}$ & $\begin{array}{l}C_{D}=C_{D_{0}}+\Delta C_{D}^{L / D} \\
C_{D}=\frac{\left(C_{D_{0}}+C_{D}\right)}{2}\end{array}$ & $\begin{array}{l}\text { no convection effect } \\
\text { convection effects }\end{array}$ \\
\hline
\end{tabular}




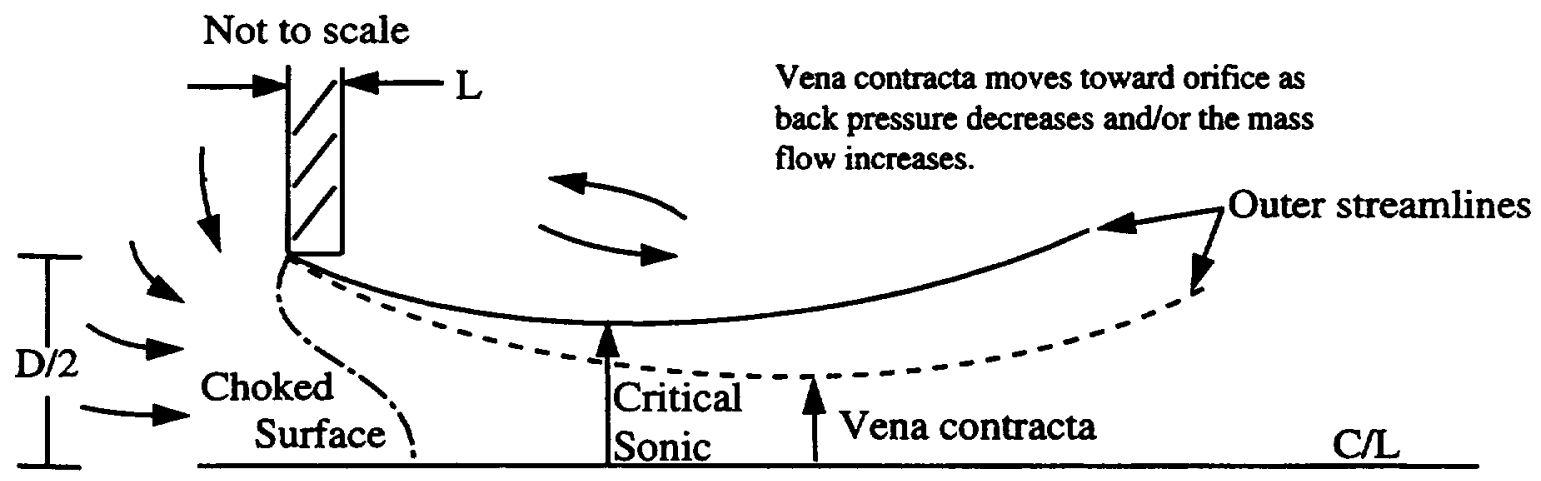

a) low $L / D ; L / D \leq 1$

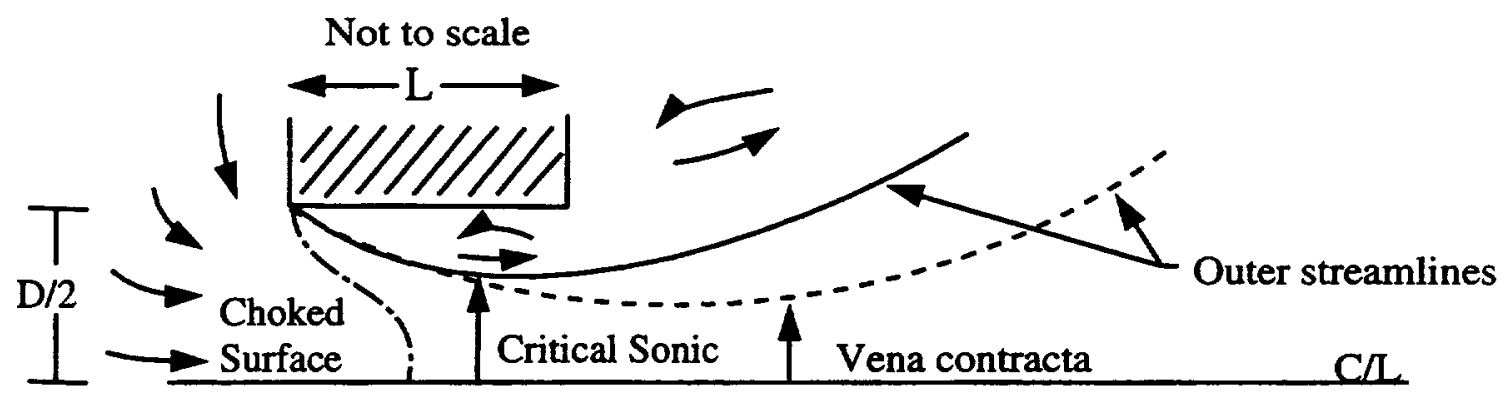

b) intermediate $\mathrm{L} / \mathrm{D} ; 1<\mathrm{L} / \mathrm{D} \leq 3$

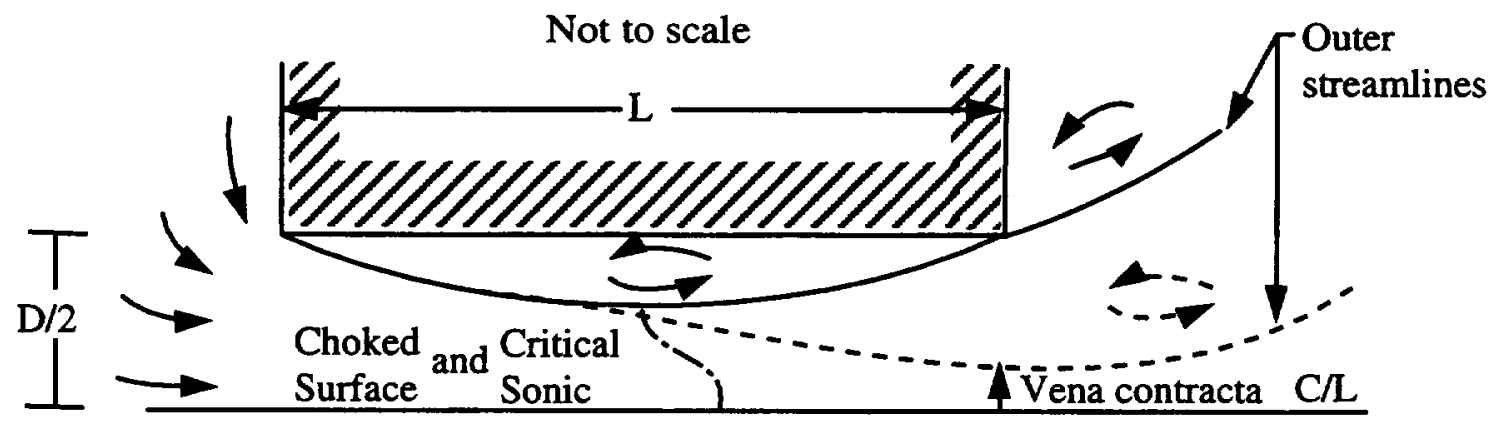

c) high L/D; L/D > 6

Fig. 1 - Schematic of vena contracta for orifice flow, no external flow: 3 mass flow levels. 


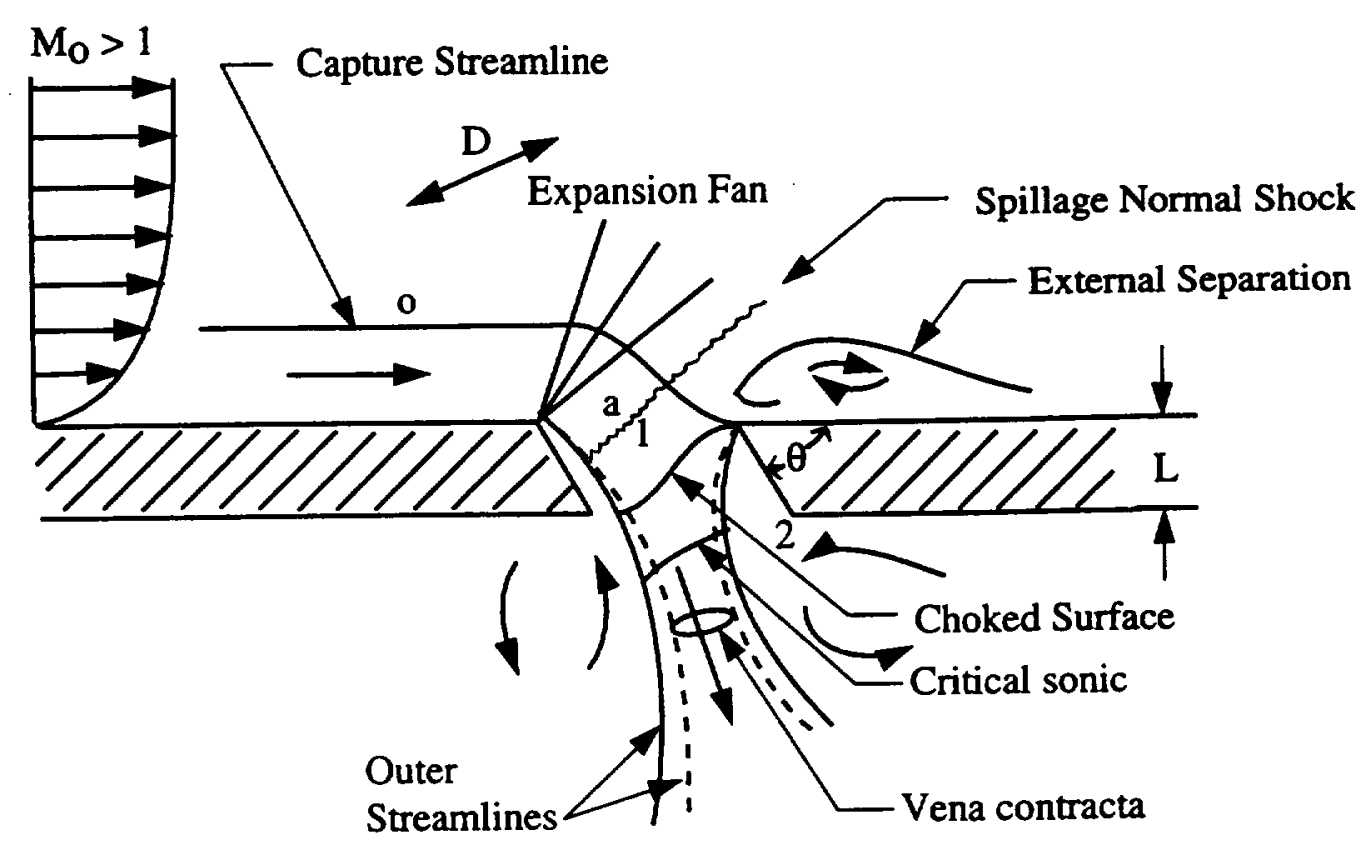

Fig. 2 Schematic of flow through angled bleed hole, centerline, $\theta>50 \mathrm{deg}$.

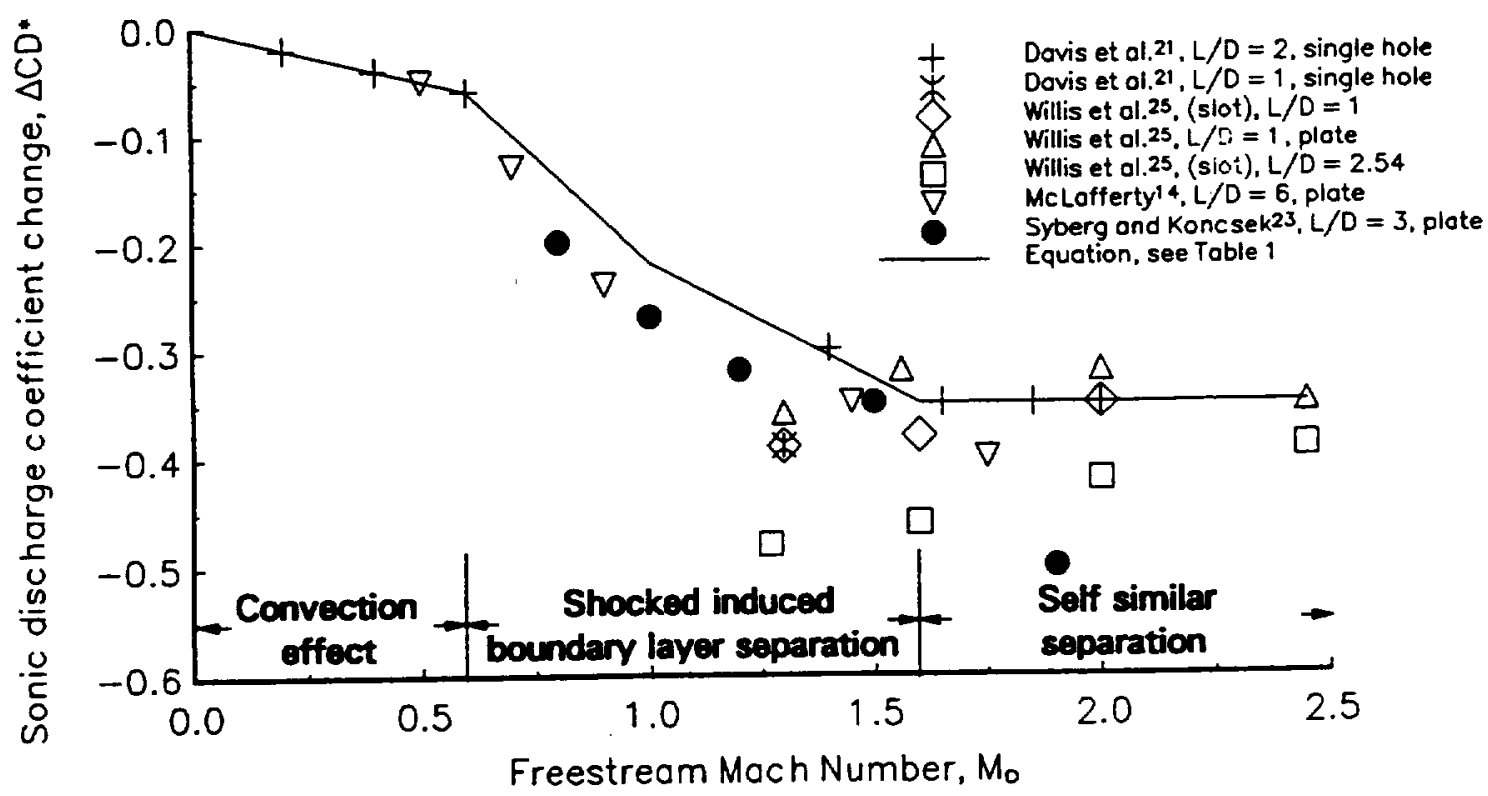

Fig. 3 Sonic discharge coefficient decrease vs Mach number, $\theta=90 \mathrm{deg}$. 


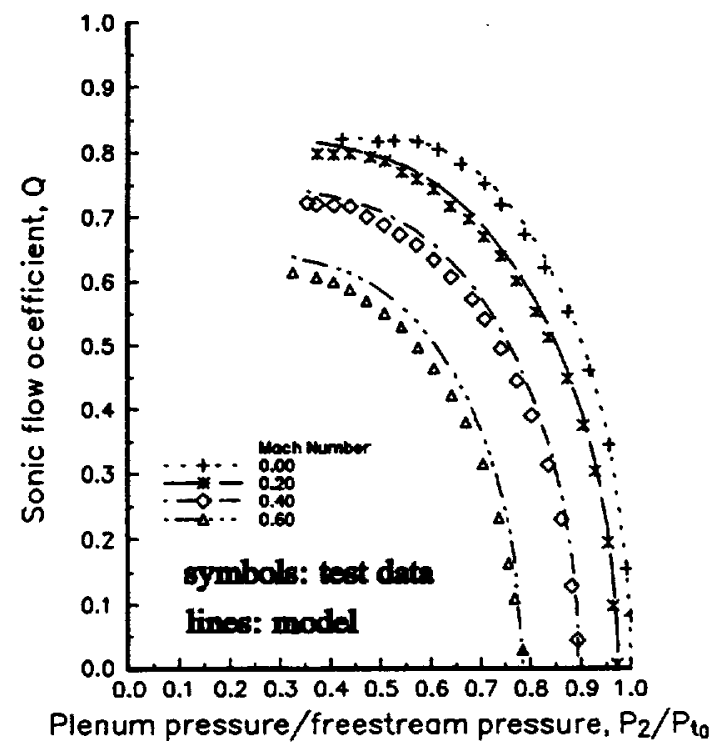

Fig. 4 Sonic flow coefficient, single 90 deg hole $L / D=2$ (Davis et al. ${ }^{21}$ test data).

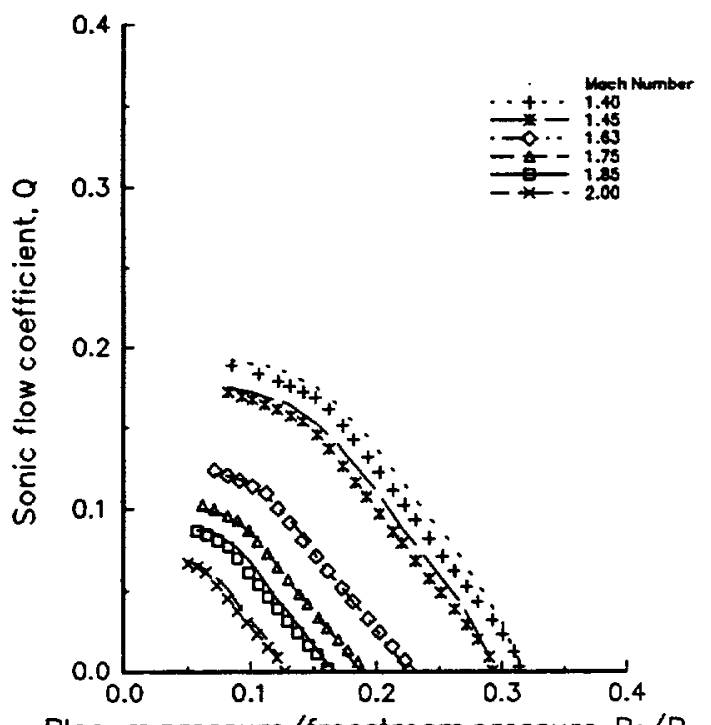

Fig. 5 Sonic flow coefficient, single 90 deg hole $L / D=2$ (Davis et ol. 21 test data).

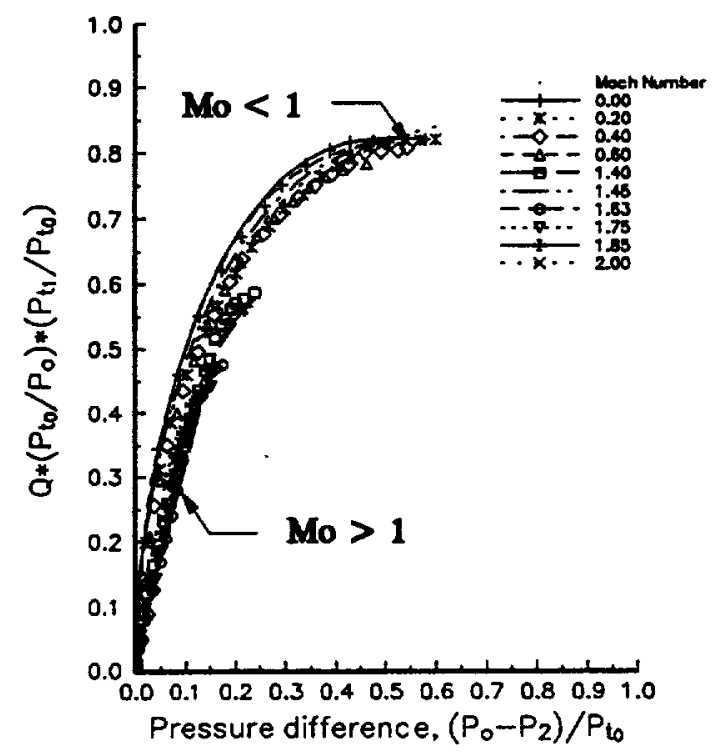

Fig. 6 Sonic flow coefficient, single 90 deg hole $L / D=2$ (Davis et al.21 test data).

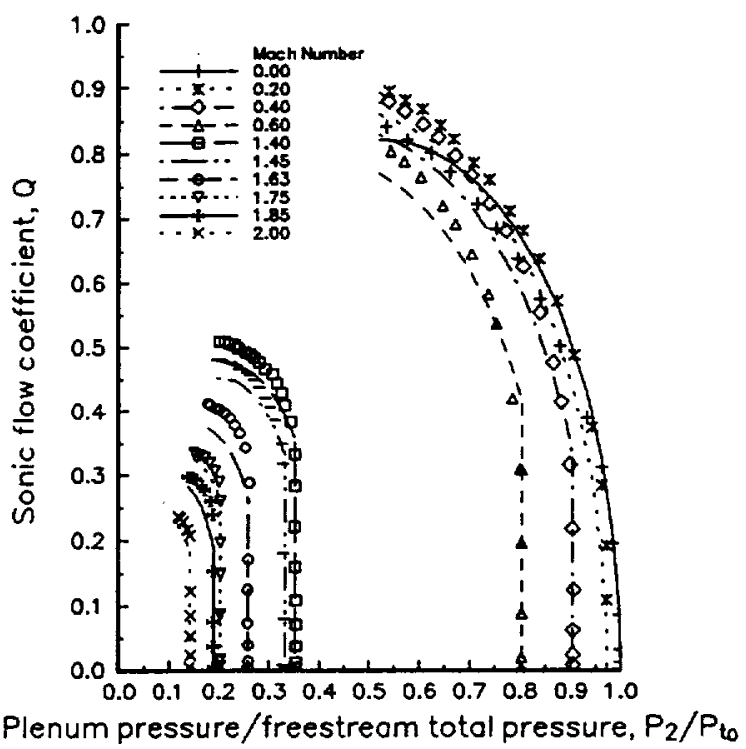

Fig. 7 Sonic flow coefficient, single 20 deg hole $L / D=2$ (Davis et al. ${ }^{21}$ test dato). 


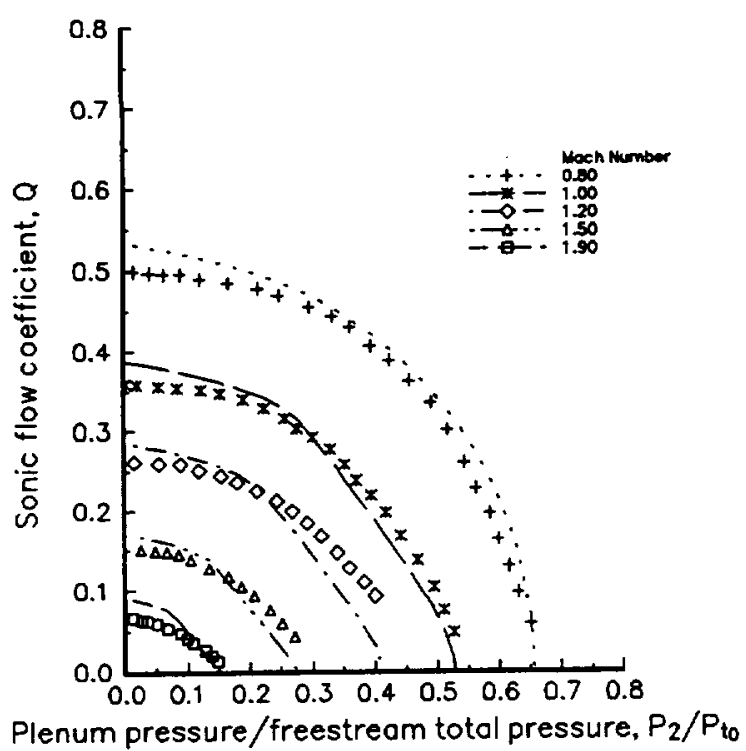

Fig. 8 Sonic flow coefficient, 90 deg plate, $L / O=3$ (Syberg and Konc sek 23 ; Dennard 24 and McLafferty ${ }^{14}$ test data).

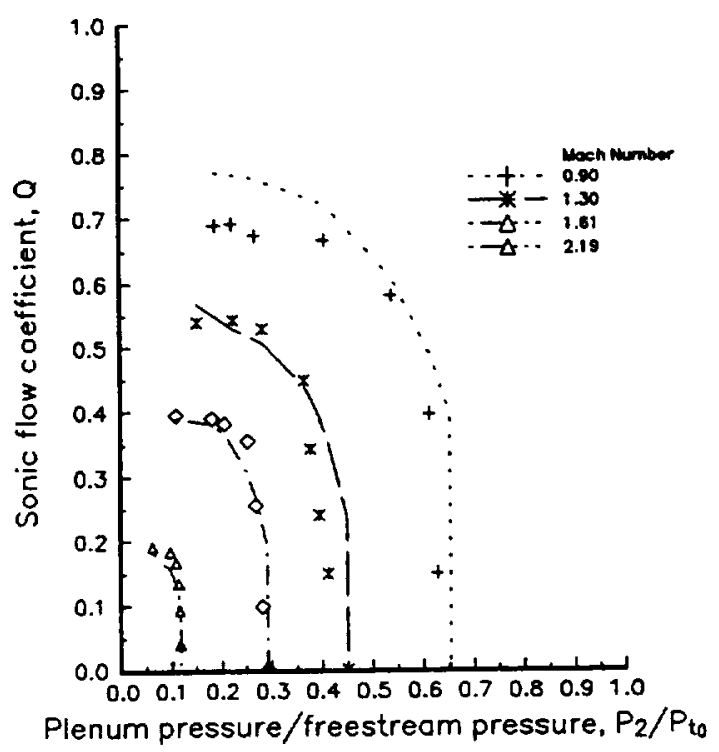

Fig. 10 Sonic flow coefficient, 20 deg plote, $L / D=3$ (Syberg and Konc sek 23 test dato).

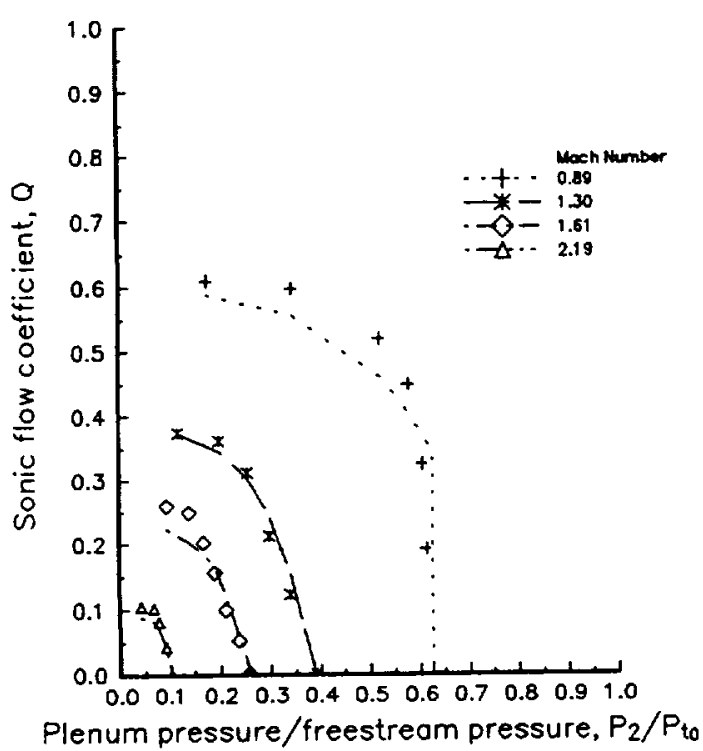

Fig. 9 Sonic flow coefficient, 40 deg plote, $L / D=3$ (Syberg and Koncsek 23 test dato).

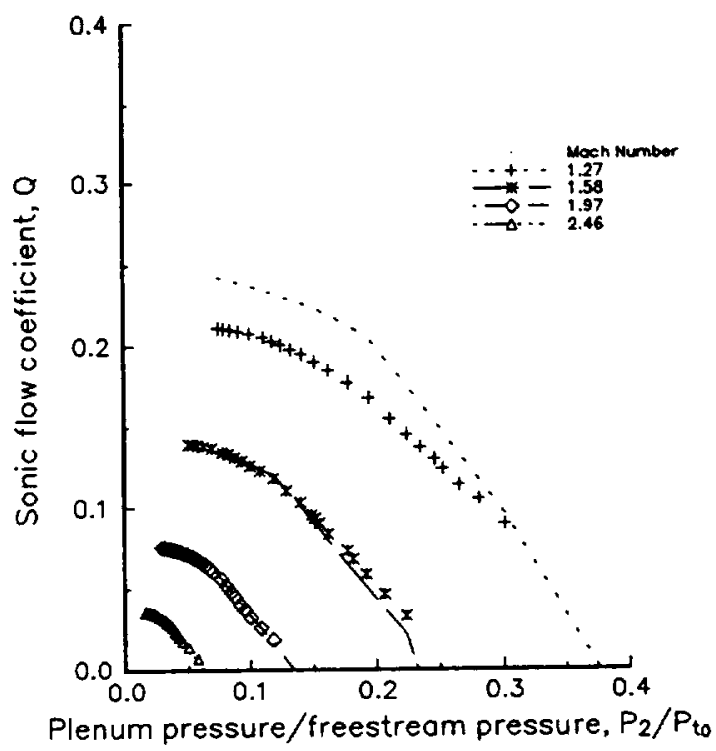

Fig. 11 Sonic flow coefficient, 90 deg plate, $L / D=1$ (Willis et al.25 test dota). 


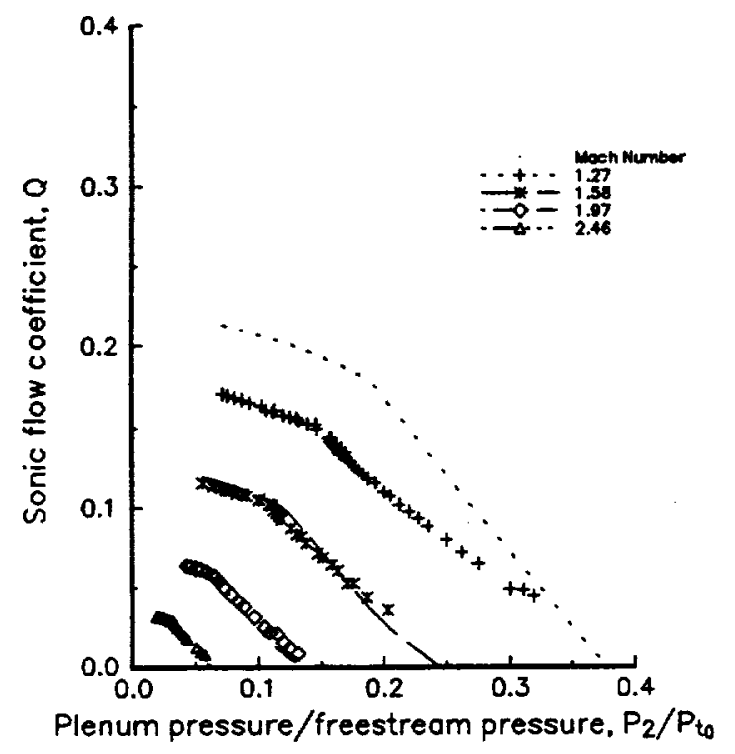

Fig. 12 Sonic flow coefficient, 90 deg slot $L / D=2.54$ (Willis et al.25 test dato).

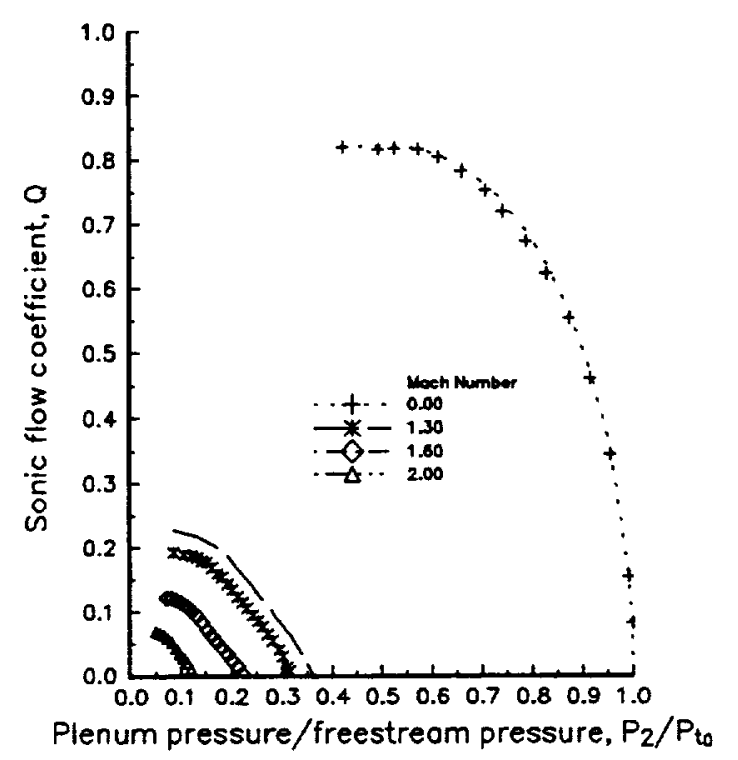

Fig. 13 Sonic flow coeffic ient, single 90 deg hole, $L / D=1$ (Davis et al.21 test data).

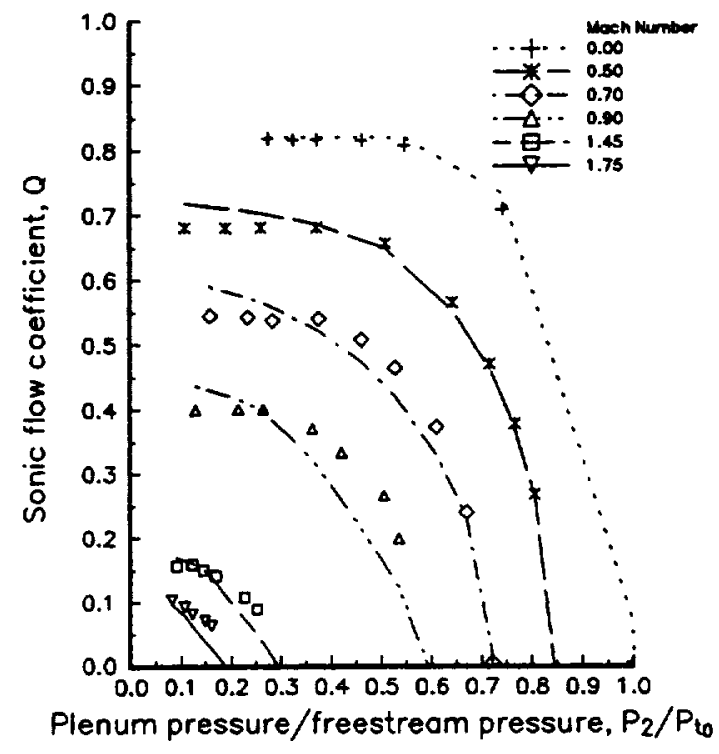

Fig. 14 Sonic flow coefficient, 90 deg plate $L / D=6$ (McLofferty ${ }^{14}$ test doto).

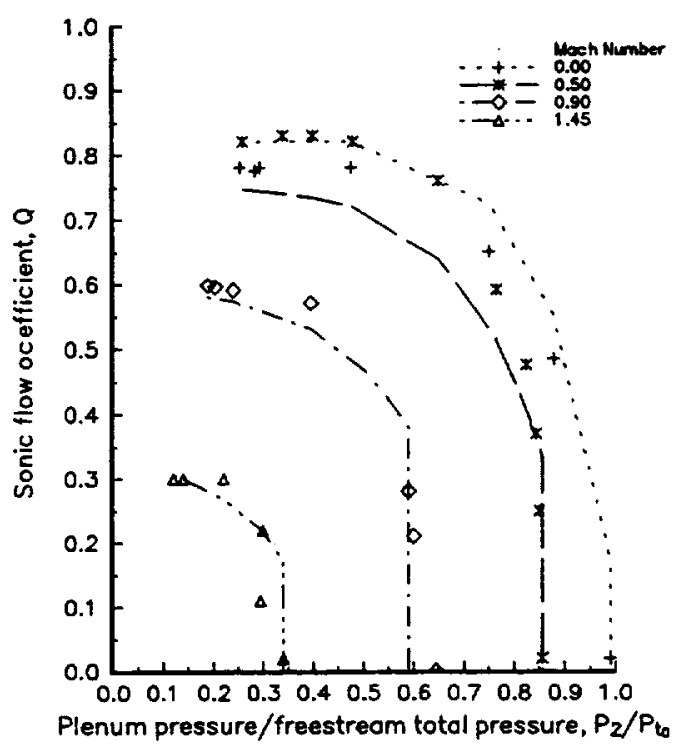

Fig. 15 Sonic flow coefficient, 40 deg plate $L / D=6$ (McLafferty ${ }^{14}$ test dato). 


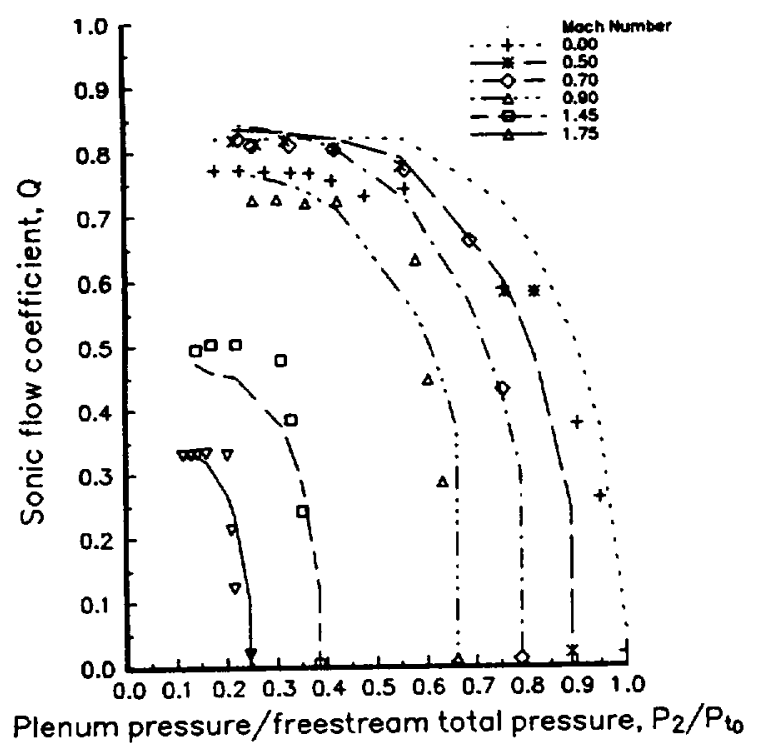

Fig. 16 Sonic flow coefficient, 20 deg plate, $L / D=6$ (Mc Lafferty ${ }^{4}$ test dato).

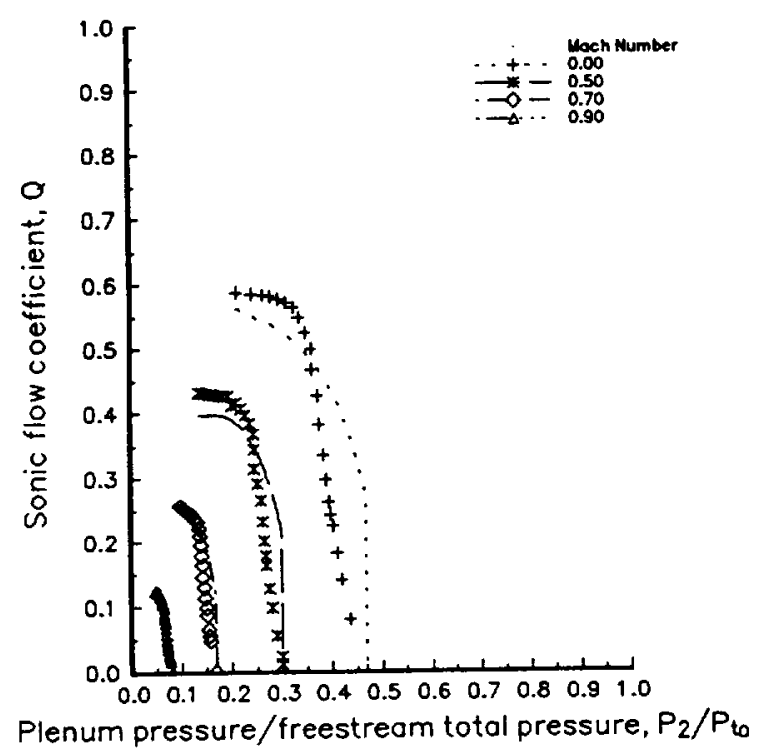

Fig. 17 Sonic flow coefficient, single 20 deg hole, $L / D=2.92$ (Davis et al.21 test data). 


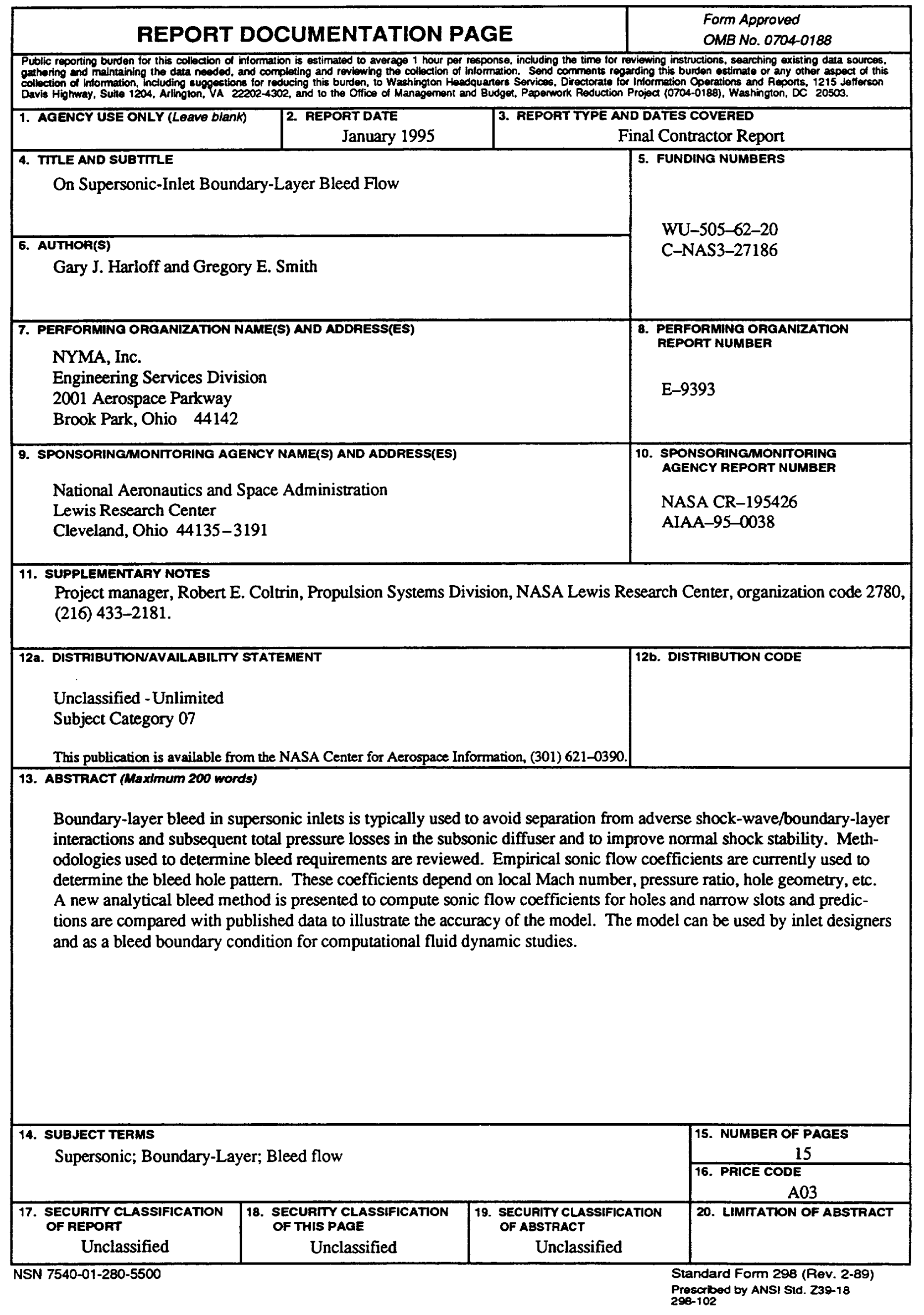




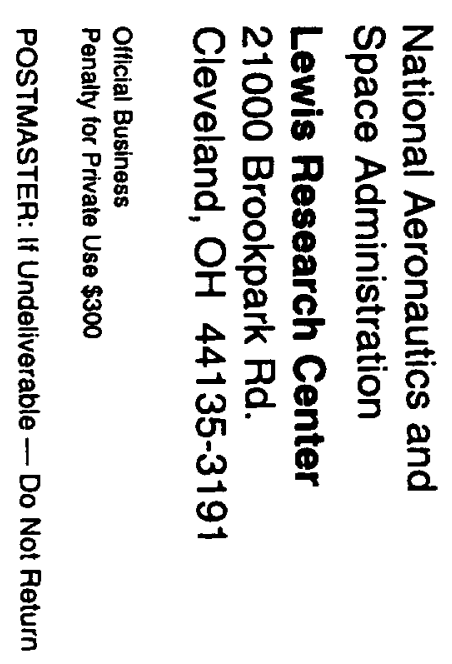


